\title{
Maternal perspectives on infant feeding practices in Soweto, South Africa
}

\author{
Stephanie V Wrottesley ${ }^{1, *}$, Alessandra Prioreschi ${ }^{1}$, Wiedaad Slemming ${ }^{2}$, \\ Emmanuel Cohen ${ }^{1,3}{ }^{(1)}$, Cindy-Lee Dennis ${ }^{4}$ and Shane A Norris ${ }^{1,5}$ \\ 'South African Medical Research Council (SAMRC)/Wits Developmental Pathways for Health Research Unit (DPHRU), \\ Department of Paediatrics and Child Health, Faculty of Health Sciences, University of the Witwatersrand, Johannesburg \\ 2193, South Africa: ${ }^{2}$ Division of Community Paediatrics, Department of Paediatrics and Child Health, Faculty of Health \\ Sciences, University of the Witwatersrand, Johannesburg, South Africa: ${ }^{3}$ Unité Mixte de Recherche (UMR) 7206 \\ "Eco-anthropology", Musée de l'Homme, Paris, France: ${ }^{4}$ Lawrence S Bloomberg Faculty of Nursing, Li Ka Shing \\ Knowledge Institute, St. Michael's Hospital, University of Toronto, Toronto, Canada: ${ }^{5}$ School of Human Development \\ and Health, National Institute for Health Research (NIHR) Southampton Biomedical Research Centre, Global Health \\ Research Institute, University of Southampton, Southampton, UK
}

Submitted 20 December 2019: Final revision received 28 May 2020: Accepted 25 June 2020

\begin{abstract}
Objective: To (i) describe the infant feeding practices of South African women living in Soweto and (ii) understand from the mothers' perspective what influences feeding practices.

Design: Semi-structured focus group discussions (FGD) and in-depth interviews (IDI) were conducted, and data were analysed using thematic analysis.

Setting: Soweto, South Africa.

Participants: Nineteen mothers were stratified into three FGD according to their baby's age as follows: 0-6-month-olds, 7-14-month-olds and 15-24-month-olds. Four mothers from each FGD then attended an IDI.

Results: Although mothers understood that breast-feeding was beneficial, they reported short durations of exclusive breast-feeding. The diversity and quality of weaning foods were low, and 'junk' food items were commonly given. Infants were fed using bottles or spoons and feeding commonly occurred separately to family meal times. Feeding practices were influenced by mothers' beliefs that what babies eat is important for their health and that an unwillingness to eat is a sign of ill health. As such, mothers often force-fed their babies. In addition, mothers believed that feeding solid food to babies before 6 months of age was necessary. Family matriarchs were highly influential to mothers' feeding practices; however, their advice often contradicted that of health professionals.

Conclusions: In South Africa, interventions aimed at establishing healthier appetites and eating behaviours in early life should focus on: (i) fostering maternal self-efficacy around exclusive breast-feeding; (ii) challenging mixed feeding practices and encouraging more responsive feeding approaches and (iii) engaging family members to promote supportive household and community structures around infant feeding.
\end{abstract}

Keywords Infant feeding Qualitative South Africa
Early childhood growth and development are established predictors of developmental and health outcomes throughout life and may influence the health and well-being of the next generation ${ }^{(1)}$. Specifically, adverse exposures such as malnutrition during critical periods of developmental plasticity (first 1000 d; i.e., pregnancy and the first 2 years of life) are associated with sub-optimal growth, adiposity and developmental delays in childhood, as well as with obesity and non-communicable disease risk in later life ${ }^{(2)}$. This is particularly relevant in low- and middle-income countries such as South Africa, where both stunting and overweight/ obesity affect approximately a quarter of children under the age of $5^{(3,4)}$. Within the framework of nurturing care, both adequate nutrition and responsive parenting approaches in 
early life are critical to building a foundation for optimal growth and development through infancy and childhood ${ }^{(1)}$.

The WHO recommends exclusive breast-feeding for the first 6 months of life, with sustained breast-feeding up to 2 years of age, alongside the introduction of diverse, micronutrient-rich complementary foods in order to support optimal infant growth and development ${ }^{(1)}$. These guidelines should be complemented by responsive caregiving approaches, which involve prompt and appropriate mother/caregiver-child interactions that promote the development of healthy appetites and eating behaviours ${ }^{(1)}$. However, while guidelines for optimal infant feeding practices exist, global research shows that they are rarely achieved due to barriers such as conflicting sources of information and advice, financial constraints, convenience, misinterpretation of infant behavioural cues and lack of support and/or perceived pressure from healthcare workers, family members and friends ${ }^{(5-8)}$.

In South Africa, infant feeding guidelines and their interpretation have been strongly influenced by changes in guidelines for the Prevention of Mother-to-Child Transmission of $\operatorname{HIV}^{(9)}$. Specifically, previous guidelines provided HIV-positive women with a choice to either exclusively breastfeed or to exclusively formula feed their infants, with free infant formula also being provided to HIV-positive women in healthcare facilities. However, in 2011, the Tshwane Declaration of Support for Breastfeeding in South Africa was introduced and aimed to promote exclusive breast-feeding to all women, regardless of their HIV status, leading to a shift in the advice given to HIV-positive women, as well as an end to free infant formula provision $^{(10)}$. While policy changes reflect WHO recommendations, poor communication around these changes between policy makers, healthcare providers and mothers, as well as the stigmatisation of HIV and its established link to infant feeding practices in South African communities, continues to influence maternal decision making ${ }^{(11,12)}$

Quantitative and qualitative research conducted in South Africa has shown that, although the initiation of breast-feeding has greatly increased since 2011 (>90\%), only $32 \%$ of infants under 6 months of age are exclusively breastfed and mixed feeding is common - with non-breast milk liquids and solids often introduced before 2 months of age ${ }^{(4,11-13)}$. Potential explanations for this have been an ongoing prominence of exclusive breast-feeding education and advice around HIV (rather than infant health) and a lack of emphasis on the risks of mixed feeding ${ }^{(11)}$. While useful for understanding the context surrounding early infant feeding practices and exclusive breast-feeding rates, the focus of the literature fails to elucidate the wider context of feeding practices across the early infant period. In addition, in settings such as South Africa where approximately 14.3 million are defined as vulnerable to hunger, food insecurity and a lack of access to high quality, micronutrient-rich foods may restrict the ability of caregivers to provide adequate diets to their infants ${ }^{(14)}$. Further exploration into infant feeding practices in South Africa across the first 2 years of life - particularly related to the quality and diversity of complementary foods and their introduction as well as what influences maternal feeding practices overall therefore requires further investigation.

This qualitative study used focus group discussions (FGD) and in-depth interviews (IDI) with mothers of infants aged 0-24 months to (i) describe the infant feeding practices of urban South African women living in Soweto and (ii) understand from the mothers' perspective what influences these feeding practices.

\section{Methods}

\section{Participants}

Study participants were recruited from an existing study (the International Atomic Energy Agency multicentre infant body composition study) taking place at the South African Medical Research Council (SAMRC)/Wits Developmental Pathways for Health Research Unit (DPHRU) at Chris Hani Baragwanath Academic Hospital in Soweto, Johannesburg, South Africa. The International Atomic Energy Agency study recruited two cohorts of motherinfant pairs from the maternity ward at Chris Hani Baragwanath Academic Hospital and followed them up from either birth to 6 months ( $n$ 250) or three- to 24 months ( $n$ 400) in order to (i) develop references for infant body composition and (ii) assess factors associated with changes in body composition during infancy. Mothers involved in the current study consented to be contacted for future studies, and this platform was therefore used to identify mothers with infants across a range of infant ages ( $0-24$ months). In order to achieve a desired sample size of six to eight mothers per FGD, a total of twenty-eight mothers were randomly selected and invited to participate, with nineteen agreeing to take part in one of three FGD at the DPHRU site.

\section{Data collection}

FGD were arranged by the age of the mother's baby as follows: one each for mothers of 0-6-month-olds, 7-14month-olds and 15-24-month-olds. From those included in the FGD, twelve mothers were selected for inclusion in the individual IDI - with an even split according to the FGD that they attended. The four IDI per age group were observed to reach data saturation across all dimensions identified during the exploratory FGD phase. Prior to commencement of the FGD, all mothers completed a short questionnaire with a trained member of research staff which covered basic socio-demographic information. Both the FGD and IDI began in English - with flexibility to use vernacular languages - and were audio recorded. The FGD and IDI were all conducted by a 
qualitatively trained facilitator at the DPHRU site, while comprehensive field notes were compiled by an observer to supplement the audio files. Both the facilitator and the observer were fluent in the vernacular languages used. The focus group sessions lasted between 60 and $120 \mathrm{~min}$ each, and the interviews lasted between 60 and $90 \mathrm{~min}$ each. All participants were reimbursed for their transport costs and received refreshments when attending the FGD and IDI.

While a semi-structured guide was used to facilitate the FGD (see online supplementary material, Supplemental Appendix 1), the facilitator encouraged interaction and discussion between participants, as well as brainstorming of topics around their baby's health and well-being, movement, development and their feeding practices. This allowed for an exploratory approach to the group discussions, rather than promoting a didactic nature of posing formal questions. In addition, while the FGD were aimed at discussion of mothers' experiences with the children included in the study (i.e. within the age range of the FGD they were involved in), the open-ended nature of the FGD meant that mothers may have discussed experiences with previously born children if relevant to the conversation. Emerging themes from the FGD were then used to develop and refine the IDI guide (see online supplementary material, Supplemental Appendix 2), which was designed to provide a deeper understanding of the topics discussed during the FGD, as well as explore any gaps identified during FGD analyses. However, this interview guide remained semi-structured in order to promote open discussion and to allow for exploration into the approaches and perceptions described by mothers. After completion of the FGD and IDI, the audio files were transcribed verbatim by an external transcriber fluent in both English and the vernacular languages used. Where vernacular languages were used during the discussions, the transcriber subsequently translated the transcription to English. In order to verify accuracy, all transcripts were thoroughly checked against the recordings by either the original facilitator or observer of the FGD or IDI.

\section{Data analysis}

The three FGD transcripts were divided between three researchers who read and re-read their allocated transcript to familiarise themselves with the content. Researchers used a combination of deductive (pre-identified themes based on the research question) and inductive (emerging themes from the transcripts and field notes) approaches to identify and analyse themes. After initial identification of themes, researchers swapped transcripts and coding frameworks to cross-check interpretation and theme identification across the group. Individual-level reviews were followed by group meetings to compare, contrast and discuss emerging themes, while incorporating the principles of the immersion-crystallisation method ${ }^{(15)}$. An independent researcher tested reliability and internal validity of the data coded from the FGD and, where differences were established, reported these to the team. Discrepancies were then discussed and resolved as a group to ensure that codes and text reflected the definitions generated by the team. The independent researcher then crosschecked and collated common and unique themes across the three transcripts to develop an overall data codebook for the three FGD. Following coding, a group meeting was held to complete data analysis and interpretation of themes, and the codebook was interrogated and refined until no new themes emerged.

The codebook developed during FGD analysis was used as a basis for coding the IDI. The team of four researchers independently used the FGD codebook to analyse all twelve IDI according to four primary research areas identified from previous research and confirmed or refined based on the emerging themes from the FGD, namely (i) infant caregiving and well-being; (ii) infant feeding practices; (iii) infant movement, play and development and (iv) perceptions around infant body size. Due to the complexity of the individual research areas, these were analysed and interpreted separately, with infant feeding practices being the area of focus in this case. Where the FGD codebook did not include sufficiently detailed themes for a particular research area (i.e. infant feeding), further themes were identified and added. After coding and theme identification had been completed, a process of cross-cutting theme identification and confirmation across FGD and IDI was carried out. Once this process had been finalised per research area, the combined themes and subthemes for the FGD and IDI were shared between the research team members for interrogation of the identified themes, and these were refined and agreed upon as a group. For the purpose of the current study, only the themes and sub-themes related to infant feeding practices are presented. In order to illustrate the themes that emerged from the FGD and IDI, exemplar quotations were excerpted.

\section{Results}

The characteristics of mother-infant pairs included in the study are summarised in Table 1 . The mean ages of mothers per FGD were as follows: FGD1 ( $n$ 6), 26 (SD 4) years; FGD2 ( $n$ 7), 26 (sD 4.5) years; and FGD3 ( $n$ 6), 28 (SD 5.5) years. All mothers had attended secondary school and the majority were unemployed ( $n$ 14). Only one mother was married and lived with the baby's father. The majority of the infants were male ( $n 12)$, and the mean ages of the babies per FGD were FGD1, 4 (SD 2) months; FGD2, 9 (SD 4) months and FGD3, 19 (SD 2.5) months. 
Table 1 Characteristics of mother-infant pairs according to focus group discussion (FGD) attendance

\begin{tabular}{|c|c|c|c|}
\hline & FGD $1(n 6)$ & FGD $2(n 7)$ & FGD $3(n 6)$ \\
\hline & 0-6 months & 7-14 months & 15-24 months \\
\hline \multicolumn{4}{|l|}{$\begin{array}{l}\text { Mothers age } \\
\text { (years) }\end{array}$} \\
\hline Mean & 26 & 26 & 28 \\
\hline SD & 4.3 & 4.5 & 5.5 \\
\hline \multicolumn{4}{|l|}{$\begin{array}{l}\text { Highest level of } \\
\text { education } \\
\text { achieved, } n\end{array}$} \\
\hline $\begin{array}{l}\text { Secondary } \\
\text { school }\end{array}$ & 6 & 7 & 6 \\
\hline \multicolumn{4}{|l|}{$\begin{array}{l}\text { Total years of } \\
\text { education }\end{array}$} \\
\hline Mean & 11 & 10 & 11 \\
\hline SD & 0.3 & 0.6 & 1.0 \\
\hline \multicolumn{4}{|l|}{ Employment, $n$} \\
\hline Unemployed & 3 & 6 & 5 \\
\hline Employed & 1 & 1 & 1 \\
\hline Self-employed & 2 & 0 & 0 \\
\hline \multicolumn{4}{|l|}{ Marital status, $n$} \\
\hline Single & 5 & 7 & 6 \\
\hline Married & 1 & 0 & 0 \\
\hline \multicolumn{4}{|l|}{$\begin{array}{l}\text { Total number of } \\
\text { children, } n\end{array}$} \\
\hline 1 & 1 & 3 & 2 \\
\hline 2 & 2 & 3 & 3 \\
\hline 3 & 3 & 1 & 1 \\
\hline \multicolumn{4}{|l|}{ Infant sex, $n$} \\
\hline Male & 3 & 4 & 5 \\
\hline Female & 3 & 3 & 1 \\
\hline \multicolumn{4}{|l|}{$\begin{array}{r}\text { Infant age } \\
\text { (months) }\end{array}$} \\
\hline Mean & 4 & 9 & 19 \\
\hline SD & $1 \cdot 8$ & $3 \cdot 8$ & $2 \cdot 5$ \\
\hline
\end{tabular}

The results of the study are separated according to the two study objectives, namely (i) contextual information provided by mothers about their infant feeding practices focusing on what and how babies were being fed in Soweto and (ii) emerging themes describing maternal perspectives on what influences infant feeding practices in Soweto.

\section{Infant feeding practices}

\section{What babies are fed}

All mothers described initiating breast-feeding with their baby; however, the majority had not breastfed exclusively for any length of time. Instead, mothers introduced solid foods as early as the first or second month of life, alongside breast milk and/or formula. The first food introduced was commonly a soft maize porridge called 'cream of maize', which is a commercially purchased and fortified porridge designed as a weaning food from 6 months of age. Some mothers also gave a soft, sorghum-based porridge (known as 'Mabele') which, depending on the brand or whether it was specifically designed for weaning, may, or may not, have been fortified. For younger babies, porridge was often made very watery so that it could be fed from a bottle. Tea (usually decaffeinated rooibos) and water were also given to babies from a very young age.
As babies got older (around 5 or 6 months of age), other solid food was introduced. Common food items included commercially prepared baby foods, other cereals such as Weet-bix, bread, other maize-based porridge (pap or samp), sour milk (maas) and yogurt. Mothers with older infants discussed continuing to breastfeed and/or give infant formula past the baby's first birthday.

In general, mothers had a perception that their babies did not like vegetables and/or fruit and therefore these were rarely fed to babies up to 2 years of age. However, some mothers did feed their babies vegetables, and these were mostly starchy vegetables like pumpkin and potato. Some mothers also gave vegetables such as carrots, cabbage, spinach and beetroot to their babies when they were being cooked for the family. Specifically, at night, most babies were fed maize porridge with gravy or maas. Some were given small amounts of meat or vegetables from the family meal, but most were fed only the gravy from the family food pot.

Many mothers gave their babies 'junk' food as a snack and believed that all children liked and needed small amounts of these foods. Common snacks included crisps, sweets and lollipops, biscuits and juice, as well as other sugar-sweetened fizzy drinks. However, in some cases, yogurt (usually flavoured, sweetened yogurt) and fruit (apple and banana) were given to babies as snacks in an attempt to avoid 'junk food'.

\section{How babies are fed}

Most mothers fed their babies from their own plates or bowls, rather than from a shared plate. Young infants were commonly fed off the mother's lap using a bottle or spoon, with food often being mashed to allow them to eat it easily. Some mothers allowed their babies to begin feeding themselves once they were old enough to express a desire to do so. However, others did not allow this, as they felt their babies would play with their food rather than eat it. Babies that refused to eat were often force-fed.

Many babies in Soweto were fed 'in their own time' at home, rather than while the mother/family was eating. However, some ate together with the family during the evening meal. As many of the mothers did not have a separate dining area in their homes, feeding tended to occur where it was convenient at the time - either in the main room of the home or in the kitchen. Some mothers described feeding their babies or allowing them to eat in front of the television.

Mothers perceived fussiness and crying (or fake crying) as the most common hunger cue for babies; however, as they got older, children would tell their mothers when they were hungry or would seek out food themselves. Common cues of fullness were babies closing their mouths, spitting out their food or moving their heads away. As babies got older, they would begin playing with their food when they had eaten enough or they would tell their mothers they were full once able to vocalise this. 


\section{What influences infant feeding practices}

The factors that mothers felt influenced their infant feeding practices were identified according to ten main themes, as presented below. A complete description of the themes and sub-themes, as well as additional exemplar quotations, is provided in Table 2 .

\section{Feeding is important for a baby's health}

Across the study, mothers described an understanding that how and what babies ate was important for their health. They believed that healthy babies eat well and that feeding their babies healthy food (including breast milk), and avoiding sugary food in some cases, was a key part of keeping them healthy:

[A healthy child is] a child that is well taken care of and well fed... he eats a lot, eats well. (IDI; mother of a 1-month-old boy)

Babies who refuse to eat are unwell

Similarly, mothers perceived a lack of appetite or an unwillingness to eat as a sign of ill health:

To be able to make sure your child is eating and if they're not then to be aware that they're not and why they're not ... to understand if they don't eat, then they're sick. (FGD; mothers of 15- to 24-month-olds)

\section{Breast-feeding}

Breast-feeding was determined to be the healthy and affordable option for infant feeding. Mothers specifically described breast-feeding as 'good' or 'healthy' for the baby across the study, with those in the FGD also perceiving it to be the convenient and affordable option:

I think breastfeeding is the most affordable and healthiest thing to consider for the baby. (FGD; mothers of 0 - to 6-month-olds)

If you breastfeed your baby, she'll become healthier than one who drinks Nan [formula milk]. (IDI; mother of a 17-month-old boy)

However, during the FGD, mothers also acknowledged that breast-feeding can be challenging for some mothers. They described experiences (either personally or from the community) of mothers being unable to produce enough milk for their babies, as well as difficulties in being able to breastfeed babies in public places or once they returned to work:

Some ladies, they want to breastfeed but they have no milk in their breasts, others want to breastfeed but maybe they're at work. (FGD; mothers of 0 - to 6-month-olds)

Some people get sick when they see you taking out your breast, they say "sies, why you don't buy your child a bottle or something" ... like more in public places ... they don't like it. (FGD; mothers of 0 - to 6-month-olds)

\section{Mixed feeding}

Particularly during IDI, women discussed that mixed feeding is common practice in the community, with many mothers combining breast-feeding with formula and/or other liquids and solids from an early age:

At home there were people using the bottle, but also breastfeeding. (IDI; Mother of a 4-month-old girl)

When I started, I used to feed him formula and breast milk, and then from 4 months I started giving him Nestum, and cream of maize, and ProNutro... (IDI; mother of a 6-month-old boy)

Mothers described their mixed feeding practices - and the early introduction of solid food in particular - being influenced by a belief that babies need solid food before 6 months. Specifically, there was a strong perception that if their babies were only fed milk for 6 months that they would not feel full and may lose weight:

Anyway, we do feed our children solids because milk doesn't make them full. (FGD; mothers of 15- to 24-month-olds)

If my child was 6 months without eating solids, he'd be skin and bones only not chubby as he is now. (FGD; mothers of 0 - to 6-month-olds)

\section{Feeding soothes babies}

Infant feeding and weaning practices were also influenced by the baby's behaviour, with mothers expressing an understanding that feeding their babies would stop them from being fussy or crying. To an extent, mothers saw feeding as a way of soothing a 'problematic' baby and also believed that feeding would promote sleep:

They give us problems, they just cry and cry, but if you feed them, they are alright, they don't bother you and cry incessantly. (IDI; mother of a 4-monthold girl)

\section{Feeding routines/schedules}

Mothers expressed contrasting feelings around the idea of feeding babies according to a routine/schedule. Specifically, some mothers thought that feeding routines/schedules were useful and/or good for babies, either making babies less of a 'hassle' or ensuring that they grew properly:

They say that when you feed them at the right time [they will be normal body weight], maybe in the morning something and then in the afternoon something different and then later as well something different. (IDI; mother of a 4-month-old girl)

In contrast, some mothers felt that babies cannot and/or should not be fed according to a routine/schedule, believing that babies eat when they are hungry and you cannot 'control' them. Feeding routines/schedules were also perceived as too restrictive in some cases - with some mothers believing that they would prevent their baby from being able to adapt to change: 
Table 2 Emerging themes, sub-themes and exemplar quotations related to mothers' perceptions of what influences infant feeding practices in Soweto, South Africa

\begin{tabular}{ll}
\hline $\begin{array}{l}\text { Theme/sub-theme } \\
\begin{array}{l}\text { Feeding is important for a } \\
\text { baby's health }\end{array}\end{array}$ & $\begin{array}{c}\text { A child's health is about what they eat, how they're } \\
\text { growing ... (Mothers of 6- to 15-month-olds) }\end{array}$ \\
& $\begin{array}{l}\text { Wellbeing is how you give your baby healthy food. } \\
\text { (Mothers of 6- to 15-month-olds) }\end{array}$ \\
$\begin{array}{l}\text { Babies who refuse to eat are } \\
\text { unwell }\end{array}$ & $\begin{array}{l}\text { A child's wellbeing is when they don't give you } \\
\text { problems, like when you feed them, they eat } \\
\text { properly and everything is well. (Mothers of 6- to } \\
\text { 15-month-olds) }\end{array}$
\end{tabular}

Breast-feeding

Breast-feeding is the healthy and affordable option

Breast-feeding can be challenging for some mothers

\section{Mixed feeding}

Mixed feeding is common practice in the community

Babies need solid food before 6 months

Feeding soothes babies

Feeding routines/schedules Feeding routines/schedules are useful and/or good for babies
I think breastfeeding, I like it because, it's fast ... you don't have to wait for the bottle to be of 0 - to 6-month-olds)

I still breastfeed my child, she's still young... if I stop breastfeeding early then my child will fall ill quickly, so she needs the breast milk. (Mothers of 6- to 15-month-olds)

I tried everything to increase my breast milk. (Mothers of 6- to 15-month-olds)

You can breastfeed and at the same time get the formula. (Mothers of 0 - to 6-month-olds)

It's like that clinic card, it says you start feeding the child solids at 6 months, but at home my mom told me at 2 months we can feed the child because breast milk doesn't satiate the child. (Mothers of 0- to 6-month-olds)

Kids who breastfeed don't get full, and I fear mine will lose weight hence she's always breastfeeding. (Mothers of 15- to 24-month-olds) cold ... it's fast like, the baby is crying. (Mothers

Individual interviews

They [mothers] must give them [babies] healthy food like fruits and purity, things that are healthy, but they mustn't have a lot of sugar... when my child was eating porridge, I didn't add sugar to it. (Mother of a 23-month-old boy)

Yes, I breastfeed him, feed him properly and I make him drink water [to keep him healthy]. (Mother of a 19-month-old boy)

If he doesn't eat, I can tell that he's changed [is not well]. (Mother of a 13-month-old boy)

I take her to the clinic [if she doesn't want to eat], it means that there's something wrong. (Mother of a 17-month-old boy)

Breast milk, often, children that don't breastfeed I see them as being unhealthy... they're not energetic, like compared to the ones that breastfeed. (Mother of a 12-month-old boy)

Breast milk is good for the baby. (Mother of a 13-month-old boy)

They [other women in the community] also say you need to feed your child [solid food], you see... they tell you; you need to feed the child. (Mother of a 19-month-old boy)

I saw that my child is big and if I don't feed him then I'm starving him, so I fed him. (Mother of a 23-month-old boy)

They [mothers in the community] feed them early ... I'm talking from experience... they say the children don't get full. (Mother of a 19-monthold boy)

Even me, I believe that if I give my child food, he'll stop crying at night. (Mother of a 2-month-old girl)

Yes, he wasn't getting full, because when he's full he's supposed to fall asleep, so when he's breastfed and [you] try to put him to sleep he'd start crying, then you look to see if maybe feeding him porridge will work ... then shortly after he falls asleep. (Mother of a 19-month-old boy)

Ja, I think for me it [a schedule] works... even with food I mean it's just that sometimes your child doesn't have an appetite for what you prepared for them at home, but they eat at a certain time if it's at 8 in the morning then that's when they eat and then they sleep and they wake up maybe after $1 \mathrm{~h}$, then they eat again and feed on the milk, I think... (Mothers of 15- to 24-month-olds)

I think it [a schedule] works even now, with my child ... my child is a skinny little thing that dislikes eating, so at crèche she eats, because at crèche they eat at a certain time...I think that's the routine. (Mothers of 15- to 24 -month-olds)
Yes, every day, even when he's visiting someone else, I call them and tell them when he must eat, because if you feed him at a different time, he becomes a hassle or he refuses to eat. (Mother of a 23-month-old boy)

For me I feed him on schedule, I think it's right to feed a child on schedule; because with pooping, you'll know that at such a time the child will poop, only when you feed the child on schedule. (Mother of an 8-month-old boy) 
Table 2 Continued

\begin{tabular}{|c|c|c|}
\hline Theme/sub-theme & Focus groups & Individual interviews \\
\hline $\begin{array}{l}\text { Babies can't and/or } \\
\text { shouldn't be fed according } \\
\text { to a routine/schedule }\end{array}$ & $\begin{array}{l}\text { You can't control them [babies]... (Mothers of } \\
\text { 15- to 24-month-olds) }\end{array}$ & $\begin{array}{l}\text { Yoh, I don't know... he eats anytime... because } \\
\text { now he eats chips, suckers, and all that you } \\
\text { know; sometimes... if someone is eating pap he'll } \\
\text { eat it, that person is eating that and he wants it. } \\
\text { (Mother of a 19-month-old boy) }\end{array}$ \\
\hline \multirow[t]{2}{*}{$\begin{array}{l}\text { Babies who won't eat } \\
\text { should be force fed }\end{array}$} & $\begin{array}{l}\text { When your child is full, you still need to feed } \\
\text { them... (Mothers of 6- to 15-month-olds) }\end{array}$ & $\begin{array}{l}\text { He closes his mouth [when he is full] and when } \\
\text { I force him, he spits the food because he doesn't } \\
\text { want it. (Mother of a 6-month-old boy) }\end{array}$ \\
\hline & $\begin{array}{l}\text { Mine doesn't give me trouble when we eat because } \\
\text { when I put her in a high chair she doesn't have a } \\
\text { chance of getting up, so... you're happy. } \\
\text { (Mothers of } 15-\text { to } 24 \text {-month-olds) }\end{array}$ & $\begin{array}{l}\text { I check up on him, I make the food and see if he } \\
\text { doesn't want to eat, if he doesn't and I see that } \\
\text { it's time for him to eat I force him. (Mother of a } \\
\text { 13-month-old boy) }\end{array}$ \\
\hline \multirow[t]{2}{*}{$\begin{array}{l}\text { Mothers don't feel } \\
\text { supported by nurses } \\
\text { around infant feeding }\end{array}$} & & $\begin{array}{l}\text { No, we didn't tell them [the nurses that they were } \\
\text { feeding solids before } 6 \text { months] because they'd } \\
\text { shout at us. When the nurses ask, l'd just say I } \\
\text { only breastfeed him. (Mother of a 13-month-old } \\
\text { boy) }\end{array}$ \\
\hline & & $\begin{array}{l}\text { They [the nurses] tell us to start feeding the child } \\
\text { solids in } 6 \text { months but some people don't wait that } \\
\text { long, they just say "no these nurses are messing } \\
\text { us around they want our kids to be thin" and then } \\
\text { when they're too thin they complain at the clinic } \\
\text { that the kids are losing weight and you feed them } \\
\text { anytime. (Mother of a 6-month-old boy) }\end{array}$ \\
\hline \multicolumn{3}{|l|}{ Family matriarchs } \\
\hline $\begin{array}{l}\text { Family matriarchs are the } \\
\text { most important source of } \\
\text { advice on infant feeding }\end{array}$ & $\begin{array}{l}\text { Uhm, like what type of food I give my child and the } \\
\text { quality of food, as well as age appropriate foods } \\
\text { for my child [type of advice given by her mother]. } \\
\text { (Mothers of 6- to 15-month-olds) }\end{array}$ & $\begin{array}{l}\text { Because she [her mother] knows best, she had } 5 \text { of } \\
\text { us [children] so she'll never wrong me. At the } \\
\text { clinic they'll tell you to feed the baby at } 6 \text { months, } \\
\text { what's that? Is there a baby who doesn't eat for } \\
6 \text { months? Geez ha-a, and they [the nurses } \\
\text { themselves] feed their babies? (Mother of } \\
\text { a 7-month-old girl) }\end{array}$ \\
\hline $\begin{array}{l}\text { Family matriarchs most } \\
\text { commonly assist mothers } \\
\text { as caregivers }\end{array}$ & & $\begin{array}{l}\text { My, my [grand]mother... I stay with her, she helps } \\
\text { me with the baby, ja. (Mother of a 2-month-old } \\
\text { girl) }\end{array}$ \\
\hline & & $\begin{array}{l}\text { My mom used to take care of my baby like I used to } \\
\text { just feed her when she's crying. My mother used } \\
\text { to bath her, make her sleep, I only fed her and } \\
\text { sometimes changed nappies because I was still } \\
\text { scared of the baby when she was still } \\
\text { young... ha she wasn't tiny I was just scared that } \\
\text { if I touch her maybe her bones would break. } \\
\text { (Mother of a 17-month-old boy) }\end{array}$ \\
\hline \multicolumn{3}{|l|}{ Decision making } \\
\hline $\begin{array}{l}\text { Mothers make the final } \\
\text { decisions on how to feed } \\
\text { their babies }\end{array}$ & & $\begin{array}{l}\text { It's me [making the decisions] ... I know most about } \\
\text { the child, because l'm the mother. (Mother of a } \\
\text { 4-month-old girl) }\end{array}$ \\
\hline $\begin{array}{l}\text { Fathers don't have a role in } \\
\text { how babies are fed }\end{array}$ & & $\begin{array}{l}\text { No, they [the father] listen[s] to what I say about } \\
\text { what the child needs. (Mother of a 4-month-old } \\
\text { girl) }\end{array}$ \\
\hline
\end{tabular}

My child needs to eat at different times so that she gets used to change, like my child will eat porridge and then if you give her a banana she'll eat it and if you give her water she'll take it, so she doesn't have a time schedule, she eats anytime. (FGD; mothers of 6-to 15-month-olds)

My child doesn't have a schedule for eating; she eats when she's hungry. (FGD; mothers of 6- to 15-month-olds)

\section{Babies who will not eat should be force fed}

Across the study, mothers discussed believing that babies should be force-fed when they refused to eat:
I force him [when he won't eat] then he spits it out... I pick him up, squeeze him and feed him [using her hand]. (IDI; mother of a 19-month-old boy)

In addition, while use of high chairs was rare, a couple of mothers in the FGD described using these as a tool to force their children to eat, thereby limiting their ability to move around and avoid eating:

Because when I put her under my arm, when I feed her once she tries to get up... so when I feel that she's giving me too many problems I put her in the high chair, I know in the high chair she doesn't go forward and she doesn't go back. (FGD; mothers of 15 - to 24-month-olds) 


\section{Family matriarchs}

Throughout the study, mothers explained that family matriarchs are the most important source of advice on infant feeding in Soweto. In particular, their own mothers and grandmothers routinely promoted mixed feeding, and mothers reported experiencing a lot of pressure from maternal figures to introduce solids before 6 months of age:

They also say you need to feed your child, you see, especially the older ones, the grannies, those are the ones I take most of the advice [from] ... (IDI; mother of a 19-month-old boy)

In addition, as the advice provided by family matriarchs often conflicted with that received at health facilities, women often prioritised the advice from their babies' grandmothers and great-grandmothers above that of health professionals. This was commonly influenced by the fact that they either trusted in the experience of their mothers and grandmothers or they felt pressured to follow this advice within the home environment where they lived with, and received support from, these matriarchs:

We have parents [mothers, grandmothers] that guide us through their experience of raising us, I believe they know what's good for our kids. (FGD; mothers of 6- to 15-month-olds)

Yoh, I don't know ... because I'm scared of my grandmother, she's helping me and she's like you have a baby, I was there when you were a baby ... like "I raised you" ... I stay with her, and at night she's there; so if I don't listen to her when she says I must feed the baby, and like maybe if like the child is crying, she won't take that child, she'll be like, 'I told you that you must feed that baby, I told you ..." (IDI; mother of a 2-month-old girl)

Women who attended the IDI also explained that, in their community, as well as being the primary source of information and advice around infant feeding, family matriarchs most commonly assisted mothers as caregivers. As these women took care of their babies when the mothers needed support, they were often highly influential in the feeding methods adopted - routinely carrying out these practices in the home environment:

By then I didn't know anything; so, she [her mother] helped me, she looked after them [her children]; she was always by my side. (IDI; mother of a 19-monthold boy)

\section{Mothers do not feel supported by nurses around infant feeding}

The majority of mothers expressed a lack of support from nurses around the feeding practices they adopted, leading to a lack of trust and honesty between nurses and mothers. Nurses strongly emphasised the need to exclusively breastfeed until 6 months of age and mothers expressed feeling pressured to do so when attending health facilities.
However, as the information and advice given to them by nurses often contradicted that of their babies' grandmothers and great-grandmothers, it was common for mothers to lie to health professionals about how they were feeding their babies in an effort to avoid judgement - or even to avoid being shouted at or threatened by nurses during clinic visits:

No, like I can't say that, yoh, this nurse will be like, "I told you to do this [exclusively breastfeed] and you do this..." like now the whole clinic is looking at me, yoh . . Ja, she'll make noise, no . . Ja, ja I don't want to be judged. (IDI; mother of a 2-month-old girl)

They [other mothers] won't say [that they are feeding their babies solids before 6 months], they won't, they're scared; and the nursing sisters tell you that if you feed the child solids before they're 6 months old and it harms the child, we're going to have you arrested, we won't take it lightly, so how can you tell the truth...y you just keep quiet and tell them you didn't feed the child. (IDI; mother of a 6-monthold boy)

\section{Decision making}

Regardless of the advice that was received around infant feeding, some women expressed a strong feeling that mothers make the final decisions on how to feed their babies:

Me [makes the decisions] ... yes, they have an input but if I don't agree with them, I still have the final say. (IDI; mother of an 8-month-old boy)

In addition, the view that fathers do not have a role in how babies are fed was expressed. Women therefore felt that there was no difference in how babies were fed if their fathers were present or not:

Uh, no... as the mother you can do most of the things, you don't need [the father]. (IDI; mother of a 1-month-old boy)

However, there was some acknowledgement during IDI that fathers could provide financial support if they were involved in the lives of mom and baby which would be beneficial in providing for the baby's needs:

It would be different [if I lived with my partner] because even his support we would receive, rather than being alone and not working...financially, I'm just not able to make ends meet, because I have no income, I'm raising him on grant money, so if he was there, supportive and giving us money, I'd be able to give the child some of the things he needs. (IDI; mother of a 12-month-old boy)

\section{Discussion}

This qualitative study aimed to describe the infant feeding practices of mothers living in Soweto, South Africa, and to 
explore their perspectives on what influences these. Our findings showed that, while mothers understood that breast-feeding was beneficial, the duration of exclusive breast-feeding was very short. The diversity and quality of weaning foods was low and 'junk' food was commonly given. Babies were routinely fed using bottles or spoons and this often happened separately to family meal times.

Feeding practices in Soweto were strongly influenced by a belief in the importance of feeding for health, with an unwillingness to eat being a sign of ill health. As such, it was common for mothers to force-feed their babies. Mothers also believed that feeding solid food was necessary to soothe babies. Feeding practices were highly influenced by family matriarchs, and mothers did not believe that fathers had a role in making feeding decisions. Mothers did not feel supported by nurses and therefore tended to lie about their feeding methods at health facilities.

\section{Mixed feeding and the early introduction of solid foods}

Exclusive breast-feeding has been a focus of infant feeding literature in South Africa and, although some improvement has been demonstrated, exclusive breast-feeding to 6 months remains rare ${ }^{(16,17)}$. Continually low exclusive breast-feeding rates have, to an extent, been attributed to the historical focus on breast-feeding exclusivity for HIV-positive women and therefore the stigma that remains between exclusive breast-feeding and non-voluntary HIV disclosure ${ }^{(11)}$. Additionally, poor communication and training of health workers around policy changes have resulted in a lack of understanding of the importance of breastfeeding for infant health and development overall, as well as of the dangers of mixed feeding ${ }^{(12,18)}$. Without adequate training and investment in the guidelines that they promote, health workers tend to provide dogged emphasis on exclusive breast-feeding, seemingly removing any choice from mothers and making open discussion and support around infant feeding impossible ${ }^{(12)}$. As demonstrated in our study, a lack of support from nurses around infant feeding behaviours can lead to distrust and dishonesty between mothers and nurses. If exclusive breast-feeding interventions are to be successful, equipping health workers to educate and support mothers in an open and compassionate way is essential to facilitating greater maternal selfefficacy around exclusive breast-feeding.

The importance of an effective health workforce has been recognised as a priority in South African literature and is acknowledged globally as a part of WHO's BabyFriendly Hospital Initiative which has, in part, been responsible for positive trajectories in exclusive breastfeeding rates in middle-income settings such as Brazil ${ }^{(17,19,20)}$. While the principles behind Baby-Friendly Hospital Initiative are committed to by South Africa in our own Mother-Baby Friendly Initiative, substantial inequalities and disparities in implementation continue to isolate the most vulnerable mothers and babies ${ }^{(18,21)}$. In addition, while this intervention may successfully promote breast-feeding initiation, mothers face numerous barriers to sustained breast-feeding within their community and home environments that require ongoing promotion and support. Addressing these inequalities in the health system and its support structures - particularly in lowincome areas and at community level - should be prioritised by government if the efficacy is to be improved and sustained.

As seen in our study, complex and interrelated factors influence whether or not a mother sustains exclusive breast-feeding, with perceived breast milk insufficiency and the inadequacy of milk alone, the use of food to soothe, the involvement of other caregivers and the pressure felt from family and/or community members all contributing to the cessation of exclusive breastfeeding ${ }^{(13,17,21,22)}$. Nieuwoudt et al. ${ }^{(17)}$ recently showed that combined and complementary interventions at the individual, family, community and health facility levels are necessary to break the contextual barriers and norms surrounding exclusive breast-feeding in South Africa and promote breast-feeding self-efficacy in mothers.

In the Lancet's breast-feeding series, Rollins et al. ${ }^{(19)}$ demonstrated that, across low- and middle-income countries, adequate implementation of concurrent interventions across channels can facilitate substantial improvement in breast-feeding rates, with combined health system and community-based interventions shown to increase breast-feeding exclusivity by 2.5 times. As highlighted by our study, community norms around mixed feeding and the strong influence of family members and matriarchal figures in particular - should be targeted to promote appropriate infant feeding guidance and support. The development of well-trained peer support networks, for example, has been shown to successfully increase exclusive breast-feeding rates to 6 months of age in countries such as India, Bangladesh and the Philippines, with the frequency of contact between mothers and peer counsellors being associated with greater improvement ${ }^{(23)}$. The Grandmother Project - a non-profit organisation working to improve the health and well-being of women and children in low- and middle-income countries such as Senegal - also provides useful methodology, specifically using a 'Change through Culture' approach to utilise the role of grandmothers in their communities for the improved health and well-being of women and children ${ }^{(24)}$. This approach has been effective in strengthening the knowledge and advocacy of grandmothers around nutritional health and promoting timely and improved complementary feeding. Additionally, in Brazil, mass media campaigns and social mobilisation, alongside investment in human milk banks and policies around kangaroo-mother care, have contributed to improvements in exclusive breast-feeding and should be explored in this setting ${ }^{(19,25)}$. 


\section{Weaning and complementary foods}

While the early introduction of solid food has been explored in the literature, the diversity and quality of the complementary foods introduced during early life have received less attention, particularly with qualitative approaches and in African settings ${ }^{(26,27)}$. However, as in our study, data indicate that maize porridge and commercially produced infant cereals are most commonly given to South African infants, alongside liquids such as water and tea below 6 months of age ${ }^{(27,28)}$. In addition, porridge is often diluted to produce a thin and/or soft consistency that facilitates easier feeding, thus lowering the nutrient density per serving ${ }^{(27)}$. Use of grain-based 'gruel' and starchy staples as predominant food sources during the first 6-23 months of life is associated with poor growth in early childhood ${ }^{(29,30)}$.

The limited variety and quality of complementary foods given to babies in our study may, in part, be driven by a lack of dietary quality and diversity in the home. However, mothers' perceptions that their babies did not like certain foods (particularly vegetables) were also described to influence the weaning foods provided. As mothers associated a baby's willingness to eat and eating 'well' (i.e. eating enough) with their health and well-being, they were inclined to feed familiar and/or 'junk' foods that would be accepted and promote 'fullness' rather than novel foods that may be refused. In contexts such as Soweto, where food insecurity plagues households and regular access to high-quality, healthy food may be limited, mothers may also be reluctant to offer novel food items to infants due to the risk of refusal and, potentially, food waste ${ }^{(31)}$

Data from high-income settings show that familiarisation of new tastes through repeated exposure to novel foods is important in encouraging acceptance of new foods into the $\operatorname{diet}^{(32,33)}$. This is particularly important for bitter tastes, such as vegetables, which infants may refuse at the first exposure ${ }^{(34)}$. Specifically, greater exposure to various vegetables during weaning has been associated with reduced food fussiness and higher, more preferential, vegetable consumption in childhood ${ }^{(35,36)}$. In addition, establishment of a 'junk' food driven diet by the age of three has been associated with higher adiposity as children age ${ }^{(37,38)}$. This suggests that, particularly in increasingly obese settings such as Soweto, exposure to a variety of healthy foods, alongside minimal exposure to junk food items, during the weaning period may be important in shaping food preferences and establishing healthier trajectories of dietary intake. Therefore, interventions that encourage and support mothers (and other caregivers) towards timely and appropriate introduction of novel foods may be central to shifting emerging dietary preferences and patterns during the early years.

\section{Feeding styles}

In the era of increasing childhood obesity, there has been a growing focus on the promotion of responsive feeding which involves timely recognition and response by the caregiver to the infant's hunger and satiety cues ${ }^{(39)}$. This approach is associated with the development of appetite regulation in infants and is believed to promote healthier food relationships and reduce the risk of obesity across the life course ${ }^{(40)}$. Our study shows that mothers in Soweto have a tendency towards non-responsive feeding practices - including inappropriate responses to hunger and satiety cues, taking excess control over feeding 'events' and/or being inadequately engaged in positive feeding interactions ${ }^{(39,41)}$. Such feeding behaviours during early life have been associated with the development of unhealthy food relationships and emotional eating behaviours, as well as the adoption of poor-quality diets ${ }^{(39)}$. In addition, non-responsive feeding behaviours - such as consistent use of food to soothe - have been associated with more rapid weight gain between 6- and 18 months of age ${ }^{(39)}$.

Responsive parenting interventions indicate that providing information and support to mothers can facilitate more reactive and appropriate responses ${ }^{(40,42)}$. Specifically, guidance on contingent and developmentally appropriate feeding practices has been associated with more sensitive and structured feeding behaviours, as well as a reduction in pressured feeding styles and feeding to soothe ${ }^{(40)}$. Further, group-based anticipatory guidance with mothers has been shown to promote maternal self-efficacy and, therefore, more protective feeding behaviours and interactions ${ }^{(42)}$. This suggests that targeting styles of feeding within communities like Soweto through education and support around responsive feeding practices may promote more reactive and developmentally appropriate feeding interactions, as well as the development of healthy appetites and eating behaviours.

While the South African Department of Health provides all mothers with a Road to Health booklet which is designed to educate women in five key pillars for optimal health, the nutrition-based content largely focuses on breast-feeding and types of weaning foods, with a lack of emphasis on responsive feeding styles and the importance of support structures around infant feeding within the community. This, in addition to the effective use of such resources at health facilities, as well as the implementation of complementary health promotion messaging, should be prioritised in future government interventions ${ }^{(43)}$.

\section{Engaging fatbers in caregiving practices and support}

As seen in our study, much of the caregiving support received by mothers in communities such as Soweto is from their own mothers and grandmothers, with fathers often being absent for a variety of social and economic reasons ${ }^{(44,45)}$. While the majority of mothers in our study were single, they did not necessarily see the absence of fathers as a challenge to caregiving (with the exception of potentially providing financial support). This is common across African settings where childcare and feeding practices 
are predominantly determined by cultural norms and primarily enforced by the mother (or grandmother/ great-grandmother in some cases) ${ }^{(46)}$.

While it may not be the norm in communities such as Soweto, previous research shows that many mothers desire greater involvement and support from fathers around infant feeding ${ }^{(47)}$. In addition, research shows that involving fathers in feeding education may facilitate the adoption of a more supportive paternal role, particularly related to financial and emotional support, protection of the mother-baby dyad and encouragement to engage with health services ${ }^{(48)}$. As with family matriarchs, feeding information and support services should increasingly engage fathers where possible in order to establish optimal support structures for mom and baby. Through better engagement of all family members, we can therefore aim to reduce the isolation and uncertainty felt by individual parents and grandparents and establish a more cohesive and unified approach to infant feeding across households and communities.

\section{Strengths and limitations}

Our study presents a unique exploration into infant feeding practices during the first 2 years of life. Specifically, our findings provide novel information on the context of exclusive breast-feeding in South Africa and emphasise the complex and entrenched factors that reinforce the low likelihood of exclusive breast-feeding. In addition, by combining this with exploration into parenting styles and support structures in Soweto, we use two complementary qualitative approaches to provide a new dimension to understanding infant feeding overall.

However, the study was not without limitations. First, the FGD and IDI were conducted at our research site, and this limited our ability to validate whether what was discussed was really what happened in the community. However, through engagement with mothers of infants at a variety of ages and the use of rigorous data analysis strategies, we were able to depict major themes that were common across groups and individuals. Our study only involved mothers, rather than including other caregivers. Given the strong influence of other caregivers on infant feeding practices, future research should explore the perceived role of these individuals in supporting mothers around infant feeding, as well as how this may be enhanced to benefit infant health and development. As this was a qualitative study and only involved nineteen participants, our findings are not generalisable to the population of Soweto. However, as in all qualitative research, our objectives were exploratory in nature and therefore the three FGD and twelve IDI were effective in capturing experiences and perceptions of infant feeding behaviours and in reaching data saturation ${ }^{(49)}$.

\section{Conclusion}

The study findings highlight three key elements that may be useful for intervention development. First, a mother's confidence in her ability to exclusively breastfeed is critical and support to foster breast-feeding self-efficacy is much needed. Second, shifting the norms around mixed feeding and the early introduction of solid foods and promoting more responsive feeding approaches should play a central intervention role. Lastly, engaging family members - particularly grandmothers and greatgrandmothers, as well as fathers where possible - is important in promoting more supportive household and community structures around infant feeding and empowering mothers to make healthier choices for their infants. Given the complex interplay of factors influencing the ability of individuals to make healthy lifestyle choices for themselves and their families, prioritising the establishment of healthy appetites and eating behaviours in the early years is central to optimising the health trajectories of current and future generations.

\section{Acknowledgements}

Acknowledgements: The authors thank the mothers who took part in the current research and the research teams whose work we represent here. Financial support: S.V.W., A.P. and S.A.N. are supported by the DSI-NRF Centre of Excellence in Human Development at the University of the Witwatersrand, Johannesburg, South Africa. S.V.W. is also supported by the University Research Office and School of Clinical Medicine at the University of the Witwatersrand, Johannesburg, South Africa. The research was supported by the South African Medical Research Council and Canadian Institutes of Health Research. Conflict of interest: There are no conflicts of interest. Authorship: S.V.W. conceptualised and wrote the manuscript. A.P., W.S. and E.C. conceptualised and managed the study. S.V.W., A.P., W.S. and E.C. developed the focus group discussion and/or in-depth interview guides and analysed the data. S.A.N. was the main investigator of the project and acquired the funding. All authors were involved in interpretation of results and reviewed the manuscript. All authors gave final approval of the version to be submitted. Ethics of human subject participation: The current study was conducted according to the guidelines laid down in the Declaration of Helsinki, and all research involving study participants was approved by the University of the Witwatersrand's Research Ethics Committee (Medical; approval numbers M171129 and M170707). Written informed consent was obtained from all participants.

\section{Supplementary material}

For supplementary material accompanying this please visit https://doi.org/10.1017/S1368980020002451 


\section{References}

1. World Health Organization, United Nations Children's Fund \& World Bank Group (2018) Nurturing Care for Early Childhood Development: A Framework for Helping Children Survive and Thrive to Transform Health and Human Potential. Geneva: World Health Organization; available at https://apps.who.int/iris/bitstream/handle/10665/272603/ 9789241514064-eng.pdf?ua=1 (accessed October 2019).

2. Black RE, Victora CG, Walker SP et al. (2013) Maternal and child undernutrition and overweight in low-income and middle-income countries. Lancet 382, 427-451.

3. Shisana O, Labadarios D, Rehle T et al. (2013) South African National Health and Nutrition Examination Survey (SANHANES-1). Cape Town: HSRC Press; available at http://www.hsrc.ac.za/uploads/pageNews/72/SANHANESlaunch\%20edition\%20\%28online\%20version\%29.pdf (accessed October 2019).

4. National Department of Health (NDoH), Statistics South Africa (Stats SA), South African Medical Research Council (SAMRC) et al. (2017) South Africa Demographic and Health Survey 2016: Key Indicators. Pretoria, South Africa and Rockville, MD: NDoH, Stats SA, SAMRC, and ICF. http://dhsprogram.com/pubs/pdf/PR84/PR84.pdf (accessed October 2019).

5. Matvienko-Sikar K, Kelly C, Sinnott C et al. (2018) Parental experiences and perceptions of infant complementary feeding: a qualitative evidence synthesis. Obes Rev 19, 501-517.

6. Hoddinott P \& Pill R (2000) A qualitative study of women's views about how health professionals communicate about infant feeding. Health Expect 3, 224-233.

7. Wasser H, Bentley M, Borja J et al. (2011) Infants perceived as "fussy" are more likely to receive complementary foods before 4 months. Pediatrics 127, 229-237.

8. Shortt E, McGorrian C \& Kelleher C (2013) A qualitative study of infant feeding decisions among low-income women in the Republic of Ireland. Midwifery 29, 453-460.

9. Department of Health (2014) National Consolidated Guidelines for the Prevention of Mother-to-Child Transmission of HIV (PMTCT) and the Management of HIV in Children, Adolescents and Adults. Pretoria: Department of Health, South Africa. https://sahivsoc.org/Files/ART\% 20Guidelines\%2015052015.pdf (accessed April 2020).

10. Editorial Office (2011) The Tshwane declaration of support for breastfeeding in South Africa. South Afr J Clin Nutr 24, 214.

11. Nieuwoudt S, Manderson L \& Norris SA (2018) Infant feeding practices in Soweto, South Africa: implications for healthcare providers. S Afr Med J 108, 756-762.

12. Nieuwoudt $S \&$ Manderson L (2018) Frontline health workers and exclusive breastfeeding guidelines in an HIV endemic South African community: a qualitative exploration of policy translation. Int Breastfeed J 13, 20.

13. Mushaphi LF, Mahopo TC, Nesamvuni CN et al. (2017) Recommendations for infant feeding policy and programs in Dzimauli Region, South Africa: results from the MAL-ED birth cohort. Food Nutr Bull 38, 428-440.

14. Chakona G \& Shackleton CM (2018) Household food insecurity along an agro-ecological gradient influences children's nutritional status in South Africa. Front Nutr $\mathbf{4}, 72$.

15. Borkan J (1999) Immersion/crystallization. In Doing Qualitative Research, pp. 179-194 [BF Crabtree and WL Miller, editors]. Thousand Oaks, CA: SAGE Publications Inc.

16. Siziba LP, Jerling J, Hanekom SM et al. (2015) Low rates of exclusive breastfeeding are still evident in four South African provinces. South Afr J Clin Nutr 28, 170-179.

17. Nieuwoudt SJ, Ngandu CB, Manderson L et al. (2019) Exclusive breastfeeding policy, practice and influences in South Africa, 1980 to 2018: a mixed-methods systematic review. PLOS ONE 14, e0224029.
18. Martin-Wiesner P (2018) A Review of South Africa's Progress in Systematising Its International and National Responsibilities to Protect, Promote and Support Breastfeeding. Johannesburg, South Africa: DST-NRF Centre of Excellence in Human Development. https://www.wits.ac.za/coe-human/coeresearch-grants/coe-research-andadvocacyon-breastfeeding/ breastfeeding-policy-review/ (accessed November 2019).

19. Rollins NC, Bhandari N, Hajeebhoy N et al. (2016) Why invest, and what it will take to improve breastfeeding practices? Lancet $\mathbf{3 8 7}$ 491-504.

20. World Health Organization (2009) Baby-Friendly Hospital Initiative: Revised, Updated and Expanded for Integrated Care. Geneva: World Health Organization. http://www. ncbi.nlm.nih.gov/books/NBK153471/ (accessed November 2019).

21. Gray A \& Vawda Y (2016) Health policy and legislation. In South African Health Review [A Padarath, J King, E Mackie et al., editors]. Durban: Health Systems Trust. http://www. hst.org.za/publications/south-african-health-review-2016 (accessed November 2019).

22. Jama NA, Wilford A, Masango Z et al. (2017) Enablers and barriers to success among mothers planning to exclusively breastfeed for six months: a qualitative prospective cohort study in KwaZulu-Natal, South Africa. Int Breastfeed J 12, 43.

23. Shakya P, Kunieda MK, Koyama M et al. (2017) Effectiveness of community-based peer support for mothers to improve their breastfeeding practices: a systematic review and metaanalysis. PLOS ONE 12, e0177434.

24. Aubel J (2014) Involving Grandmothers to Promote Child Nutrition, Health and Development: A Guide for Programme Planners and Managers. Canada: World Vision International. https://grandmotherproject.org/wp-content/uploads/ 2020/04/World-Vision-Involving-Grandmothers-Guide-pdf1.pdf (accessed May 2020).

25. Santos IS, Barros FC, Horta BL et al. (2019) Breastfeeding exclusivity and duration: trends and inequalities in four population-based birth cohorts in Pelotas, Brazil, 1982-2015. Int J Epidemiol 48, Suppl. 1, i72-i79.

26. Robinson SM (2015) Infant nutrition and lifelong health: current perspectives and future challenges. J Dev Orig Health Dis 6, 384-389.

27. Sayed N \& Schönfeldt HC (2018) A review of complementary feeding practices in South Africa. South Afr J Clin Nutr 33, $36-43$.

28. Mamabolo RL, Alberts M, Mbenyane GX et al. (2004) Feeding practices and growth of infants from birth to 12 months in the central region of the Limpopo Province of South Africa. Nutrition 20, 327-333.

29. Steyn NP, Nel JH, Nantel G et al. (2006) Food variety and dietary diversity scores in children: are they good indicators of dietary adequacy? Public Health Nutr 9, 644-650.

30. Udoh EE \& Amodu OK (2016) Complementary feeding practices among mothers and nutritional status of infants in Akpabuyo Area, Cross River State Nigeria. SpringerPlus 5, 2073.

31. Ntila S, Siwela M, Kolanisi U et al. (2017) An assessment of the food and nutrition security status of weaned 7-12 months old children in rural and peri-urban communities of Gauteng and Limpopo provinces, South Africa. Int J Environ Res Public Health 14, 1004.

32. Mura Paroche M, Caton SJ, Vereijken CMJL et al. (2017) How infants and young children learn about food: a systematic review. Front Psychol 8, 1046. doi: 10.3389/fpsyg.2017.01046.

33. Anzman-Frasca S, Ventura AK, Ehrenberg S et al. (2018) Promoting healthy food preferences from the start: a narrative review of food preference learning from the prenatal period through early childhood. Obes Rev 19, 576-604.

34. Hetherington MM, Schwartz C, Madrelle J et al. (2015) A stepby-step introduction to vegetables at the beginning of 
complementary feeding: the effects of early and repeated exposure. Appetite 84, 280-290.

35. Maier-Nöth A, Schaal B, Leathwood P et al. (2016) The lasting influences of early food-related variety experience: a longitudinal study of vegetable acceptance from 5 months to 6 years in two populations. PLOS ONE 11, $\mathrm{e} 0151356$.

36. Mallan KM, Fildes A, Magarey AM et al. (2016) The relationship between number of fruits, vegetables, and noncore foods tried at age 14 months and food preferences, dietary intake patterns, fussy eating behavior, and weight status at age 3.7 years. J Acad Nutr Diet 116 630-637.

37. Reilly JJ, Armstrong J, Dorosty AR et al. (2005) Early life risk factors for obesity in childhood: cohort study. BMJ 330, 1357.

38. Leary SD, Lawlor DA, Davey Smith G et al. (2015) Behavioural early-life exposures and body composition at age 15 years. Nutr Diabetes 5, e150-e150.

39. Hurley KM, Cross MB \& Hughes SO (2011) A systematic review of responsive feeding and child obesity in highincome countries. J Nutr 141, 495-501.

40. Savage JS, Hohman EE, Marini ME et al. (2018) INSIGHT responsive parenting intervention and infant feeding practices: randomized clinical trial. Int J Behav Nutr Phys Act 15, 64 .

41. Harbron J \& Booley S (2013) Responsive feeding: establishing healthy eating behaviour early on in life. South Afr J Clin Nutr 26, S141-S149.
42. Daniels LA, Mallan KM, Nicholson JM et al. (2015) An early feeding practices intervention for obesity prevention. Pediatrics 136, e40-e49.

43. Wiles JI \& Swingler G (2018) The use of the Road-to-Health card by doctors in a tertiary paediatric hospital setting. South Afr J Child Health 12, 63-67.

44. Meintjes H, Hall K \& Sambu W (2015) Demography of South Africa's Children; available at http://www.ci.uct.ac. $\mathrm{za} /$ sites/default/files/image_tool/images/367/Child_Gauge/ South_African_Child_Gauge_2015/Child_Gauge_2015-CC_ demographics.pdf (accessed December 2019).

45. van den Berg W \& Makusha T (2018) State of South Africa's Fathers 2018. Sonke Gender Justice, Human Sciences Research Council; available at https://men-care.org/wpcontent/uploads/sites/3/2018/07/State-SA-Fathers-Report.pdf (accessed December 2019).

46. Aubel J (2012) The role and influence of grandmothers on child nutrition: culturally designated advisors and caregivers. Matern Child Nutr 8, 19-35.

47. Chintalapudi N, Hamela G, Mofolo I et al. (2018) Infant and young child feeding decision making and practices: Malawian mothers' and fathers' roles in the context of HIV. J Hum Lact 34, 68-76.

48. Mgolozeli SE, Khoza LB, Shilubane HN et al. (2018) Perceived roles of fathers in the promotion, support and protection of breastfeeding: article. AfrJ Nurs Midwifery 20, 1-19.

49. Hennink MM, Kaiser BN \& Marconi VC (2017) Code saturation versus meaning saturation: how many interviews are enough? Qual Health Res 27, 591-608. 